\title{
miR-223 decreases cell proliferation and enhances cell apoptosis in acute myeloid leukemia via targeting FBXW7
}

\author{
YI XIAO, CHANGLIANG SU and TAORAN DENG \\ Department of Hematology, Tongji Hospital, Tongji Medical College, \\ Huazhong University of Science and Technology, Wuhan, Hubei 430030, P.R. China
}

Received May 13, 2015; Accepted August 12, 2016

DOI: $10.3892 / 01.2016 .5115$

\begin{abstract}
The expression of microRNA-223 (miR-233) has been investigated in various types of cancer. However, to the best of our knowledge, the expression and function of miR-223 in acute myeloid leukemia (AML) remains to be elucidated. The expression of miR-223 was measured by reverse transcription-quantitative polymerase chain reaction. Following transfection with miR-223, cell viability assays, cell apoptosis assays, western blot analysis and luciferase assays were conducted in AML cell lines. In the present study, it was initially observed that miR-223 was downregulated in AML patients compared with healthy subjects. It was also demonstrated that miR-223 inhibited cell proliferation and enhanced cell apoptosis in AML cell lines. Additionally, the present study provided evidence that miR-223 may directly target F-box and WD repeat domain containing 7 in AML. The identification of candidate target genes of miR-223 may provide an understanding of the potential mechanisms underlying the development of AML. In conclusion, the results of the present study have therapeutic implications and may be exploited for further treatment of AML.
\end{abstract}

\section{Introduction}

Acute myeloid leukemia (AML) is an aggressive malignant disorder of hematopoietic cells that is characterized by clonal proliferation of myeloid progenitor cells and maturation arrest (1). It is the most common acute leukemia in the adult population, with a median age at the time of diagnosis of 65 years (2). Previous studies have demonstrated that AML results from mutations in multiple genes involved in cell proliferation, survival and apoptosis (3-5). Such changes

Correspondence to: Professor Yi Xiao, Department of Hematology, Tongji Hospital, Tongji Medical College, Huazhong University of Science and Technology, 1095 Jie-Fang Avenue, Wuhan, Hubei 430030, P.R. China

E-mail: xiaoyi130929@163.com

Key words: acute myeloid leukemia, F-box and WD repeat domain containing 7, microRNA-223, apoptosis ultimately result in the activation of cellular signaling pathways that promote cell growth and/or maintain survival, leading to leukemogenesis (6,7). Prognostic factors for AML include: Patient age, preceding cytotoxic treatments for a primary disorder, antecedent hematological disease and the presence of specific cytogenetic, molecular and epigenetic aberrations (8). Treatment of AML has changed little over the past three decades, with curative therapy consisting of the nucleoside analog cytarabine in combination with an anthracycline (9). However, a major complication is that the current drugs are highly toxic and poorly tolerated, particularly by older patients (10). Therefore, the identification of novel strategies for the treatment of acute myeloid leukemia is urgently required.

Over the previous few years, a novel class of small RNAs, named microRNAs (miRs), has been demonstrated to be altered in AML $(11,12)$. miRs are a large family of highly conserved non-coding RNAs with a short single strand of 19-25 nucleotides in length, which have a role in a wide range of cellular processes, including cell differentiation, apoptosis, proliferation and survival signaling pathways $(13,14)$. miRs have been demonstrated to negatively regulate gene expression by binding to the 3'untranslated region (UTR) of a target gene's mRNA, thereby degrading or blocking translation (15). Biological evidence has been observed that certain upregulated miRs in cancer may act as oncogenes, by contributing to the transformed phenotype and suppressing tumor suppressor genes (16). Furthermore, specific miRs that are downregulated in cancer may act as tumor suppressors, by allowing the expression of oncogenes (17). In previous years, functional and prognostic studies have demonstrated that miRs have a significant role in hematological malignancies, and certain miRs have been proposed as prognostic markers and therapeutic targets in the treatment of leukemia (18-21).

The expression of miR-223 has been investigated in various types of cancer, however, to the best of our knowledge the expression and function of miR-223 in AML remains to be elucidated. In the present study, it was demonstrated that miR-223 was downregulated in AML patients, and overexpression of miR-223 repressed cell proliferation and enhanced cell apoptosis by directly targeting F-box and WD repeat domain-containing 7 (FBXW7). The results of the present study have therapeutic implications and may be exploited for the development of novel treatments for AML. 


\section{Materials and methods}

Clinical specimens. The present study included 45 patients with AML (28 males and 17 females; age range, 17-73 years) and 20 healthy subjects. All patients were enrolled at the Department of Hematology, Tongji Hospital, Tongji Medical College, Huazhong University of Science and Technology (Wuhan, China), and provided written informed consent. The diagnosis and classification of AML patients were based on French-America-British and World Health Organization criteria combined to immunophenotyping and cytogenetic analysis (22-24). All patients were newly diagnosed with AML between June 2011 and September 2013 and were not taking any anti-leukemic therapy at the moment of bone marrow aspirates. The Tongji Hospital's Protection of Human Subjects Committee approved the present study.

Cell culture and transfection. The human leukemia cell lines, HL-60 and K562, were purchased from The Cell Bank of Type Culture Collection of Chinese Academy of Sciences (Shanghai, China). Cells were cultured in RPMI-1640 (Gibco; Thermo Fisher Scientific, Inc., Waltham, MA, USA) supplemented with $10 \%$ fetal bovine serum (Gibco; Thermo Fisher Scientific, Inc.), $100 \mathrm{U} / \mathrm{ml}$ penicillin G (Gibco; Thermo Fisher Scientific, Inc.), $100 \mu \mathrm{g} / \mathrm{ml}$ streptomycin (Gibco; Thermo Fisher Scientific, Inc.) and $2 \mathrm{mM}$ L-glutamine (Gibco; Thermo Fisher Scientific, Inc.) at $37^{\circ} \mathrm{C}$ in a humidified atmosphere containing $5 \% \mathrm{CO}_{2}$. Cells were routinely subcultured every 2-3 days.

Mature miR-223 and miR negative control (NC) mimics were purchased from Shanghai GenePharma Co., Ltd. (Shanghai, China). The sequence of miR-223 mimic was 5'-UGU CAG UUU GUC AAA UAC CCC A-3'. The sequence of NC mimic was 5'-UUC UCC GAA CGU GUC ACG UTT-3'. For functional analysis, cells were transfected with miR-223 mimics or NC using Lipofectamine 2000 (Invitrogen; Thermo Fisher Scientific, Inc.) according to the manufacturer's protocol.

RNA isolation, reverse transcription and reverse transcription-quantitative polymerase chain reaction (RT-qPCR). Mononuclear cells from bone marrow aspirate samples were isolated by density-gradient centrifugation ( $400 \mathrm{x} g$ for $30 \mathrm{~min}$ at $20^{\circ} \mathrm{C}$ and $100 \mathrm{xg}$ for $10 \mathrm{~min}$ at $20^{\circ} \mathrm{C}$ ) with the use of Ficoll-Paque Plus (GE Healthcare Life Sciences, Uppsala, Sweden) according to the manufacturer's protocol. Total RNA was isolated using TRIzol reagent (Invitrogen; Thermo Fisher Scientific, Inc.) and reverse transcribed to complementary DNA using a PrimeScript RT reagent kit (Takara Biotechnology Co., Ltd., Dalian, China) according to the manufacturer's protocol. An Applied Biosystems ${ }^{\circledast} 7500$ Real-Time PCR System (Thermo Fisher Scientific, Inc.) and a SYBR Premix Ex Taq ${ }^{\text {TM }}$ kit (Takara Biotechnology Co., Ltd.) were used to perform qPCR. All PCR primers were purchased from Guangzhou RiboBio Co., Ltd. (Guangzhou, China). The cycling conditions were as follows: $95^{\circ} \mathrm{C}$ for $30 \mathrm{sec}$, followed by 40 cycles of $95^{\circ} \mathrm{C}$ for $5 \mathrm{sec}$ and $60^{\circ} \mathrm{C}$ for $30 \mathrm{sec}$. Each sample was analyzed in triplicate. The data were normalized to the endogenous U6 small nuclear RNA and fold changes were calculated using the relative quantification method $\left(2^{-\Delta \Delta \mathrm{Cq})}(25)\right.$.

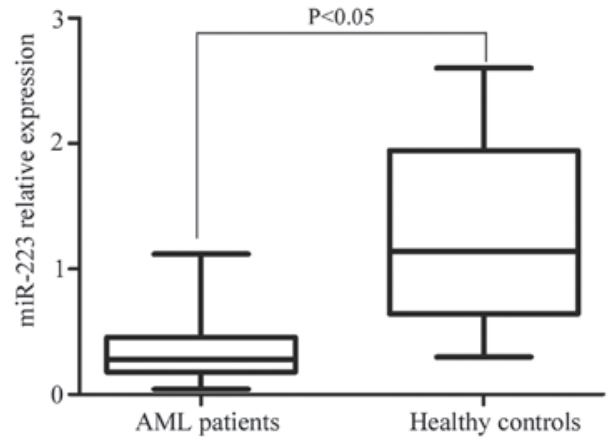

Figure 1. miR-223 was significantly downregulated in AML patients compared with healthy controls $(\mathrm{P}<0.05)$. AML, acute myeloid leukemia; miR, micro RNA.
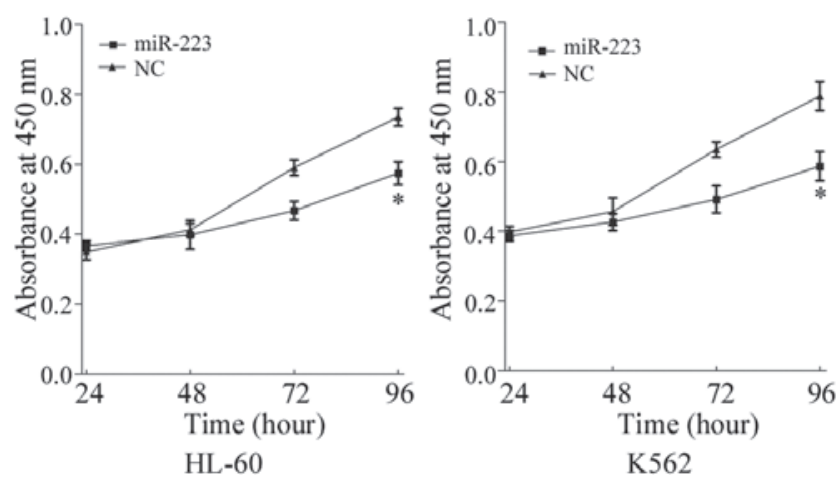

Figure 2. Cell proliferation was determined by the CCK-8 assay. CCK-8 assays revealed that upregulation of miR-223 significantly inhibited cell proliferation in acute myeloid leukemia HL-60 and K562 cell lines. CCK, cell counting kit; miR, microRNA; NC, negative control. ${ }^{*} \mathrm{P}<0.05$.

Cell viability assay. Cell viability was determined using the cell counting kit (CCK)-8 assay (Beyotime Institute of Biotechnology, Haimen, China) according to the manufacturer's protocol. Cells were seeded in 96-well culture plates at a density of $4 \times 10^{4}$ cells per well, a total of $24 \mathrm{~h}$ subsequent to transfection with miR-223 or NC. The viability of the cells was evaluated following $24,48,72$ and $96 \mathrm{~h}$ of incubation at $37^{\circ} \mathrm{C}$ in humidified air containing $5 \% \mathrm{CO}_{2}$. The absorbance of each well at $450 \mathrm{~nm}$ was measured with an enzyme-linked immunosorbent assay reader (Bio-Rad Laboratories, Inc., Hercules, CA, USA). All assays were repeated at least three times.

Cell apoptosis assay. The cells were seeded in 6-well culture plates and transfected with miR-223 or NC using Lipofectamine 2000. Following transfection for $48 \mathrm{~h}$, the cells were harvested and washed twice with phosphate-buffered saline. Following addition of $5 \mu \mathrm{l}$ of Annexin V-fluorescein isothiocyanate (FITC) and $10 \mu \mathrm{l}$ of propidium iodide (PI), cells were incubated for $15 \mathrm{~min}$ in the dark at room temperature. Cells were subsequently analyzed by flow cytometry (BD Biosciences, Franklin Lakes, NJ, USA). Apoptotic cells were classified as those exhibiting a high Annexin V-FITC fluorescence signal, with a low PI signal. The percentages of apoptotic cells were calculated by data from fluorescence activated cell-sorting analysis and the results were presented as a bar chart. 

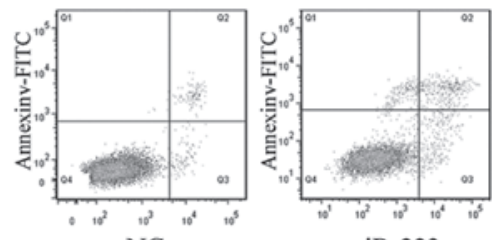

miR-223

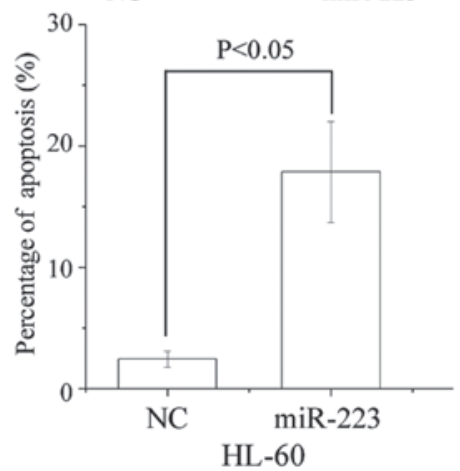

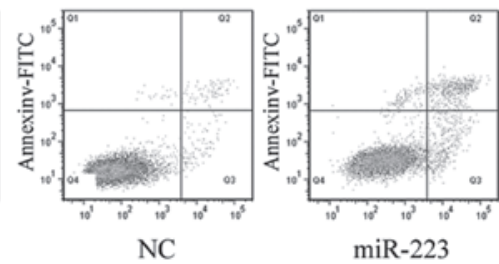

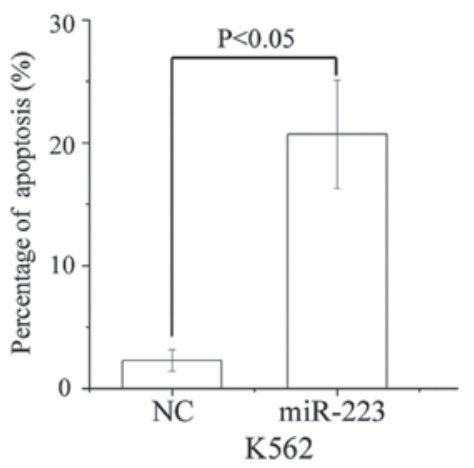

Figure 3. Effect of miR-223 on cell apoptosis was determined by flow cytometry. Upregulation of miR-223 increased cell apoptosis in acute myeloid leukemia HL-60 and K562 cells. miR, microRNA; FITC, fluorescein isothiocyanate; NC, negative control.

Bioinformatics analysis. TargetScan (http://www.targetscan. org/) was used to identify the potential targets of miR-223.

Western blotting analysis. Cells were lysed in cold radioimmunoprecipitation assay buffer (Beyotime Institute of Biotechnology) containing protease and phosphatase inhibitors and then centrifuged at $12,000 \times \mathrm{g}$ for $20 \mathrm{~min}$ at $4^{\circ} \mathrm{C}$. The samples $(20 \mu \mathrm{g})$ were then separated by $10 \%$ sodium dodecyl sulfate-polyacrylamide gel electrophoresis and transferred to polyvinylidene difluoride membranes (Beyotime Institute of Biotechnology). The membranes were blocked with Tris-buffered saline containing $0.05 \%$ Tween-20 (TBST) (Beyotime Institute of Biotechnology) containing 5\% non-fat dry milk for $1 \mathrm{~h}$ at room temperature, then incubated with primary rabbit anti-human FBXW7 antibody (1:1,000 dilution; sc-33196; Santa Cruz Biotechnology, Inc., Dallas, TX, USA) and primary rabbit anti-human $\beta$-actin antibody (1:1,000 dilution; sc-130656; Santa Cruz Biotechnology, Inc.), according to the manufacturer's protocol. The membranes were rinsed with TBST at room temperature and incubated for $1 \mathrm{~h}$ with the corresponding horseradish peroxidase-conjugated secondary antibody (Abcam, Cambridge, MA, USA) at room temperature. Protein bands were visualized using an ECL kit (Pierce; Thermo Fisher Scientific, Inc.) and analyzed using Quantity One software version 4.62 (Bio-Rad Laboratories, Inc.).

Dual luciferase activity assay. To determine whether FBXW7 is a direct target of miR-223, the luciferase activity assay vector was used. Cells were co-transfected with wild-type (WT) or mutant (Mut) 3'-UTR of FBXW7, miR-223 mimic or NC using Lipofectamine 2000according to the manufacturer's protocol. A total of $48 \mathrm{~h}$ subsequent to transfection, firefly and Renilla luciferase activities were measured using a Dual-Luciferase ${ }^{\circledR}$ Reporter Assay System (Promega Corporation, Madison, WI, USA). Each assay was replicated at least 3 times.

Statistical analysis. Data are presented as the mean \pm standard deviation, and compared using Student's t-test in Stata version 10.0 (StataCorp LP, College Station, TX, USA). P<0.05 was considered to indicate a statistically significant difference.

\section{Results}

miR-223 is downregulated in AML patients. miR-223 expression was detected by RT-qPCR in AML patients and normal controls. In the present study, it was demonstrated that miR-223 was significantly downregulated in AML patients compared with healthy controls ( $\mathrm{P}=0.014$; Fig. 1).

miR-223 reduces cell proliferation and increases cell apoptosis in AML cell lines. To investigate the effect of miR-223 on cell proliferation, a CCK- 8 assay was performed. The CCK-8 assay revealed that ectopic expression of miR-223 resulted in proliferation inhibition in AML cell lines (Fig. 2). CCK-8 assays revealed that following $96 \mathrm{~h}$ of treatment, the suppression rate of miR-223 reached $21.82 \pm 3.90 \%(\mathrm{P}=0.026)$ in HL-60 cells and $25.54 \pm 4.20 \%(\mathrm{P}=0.020)$ in $\mathrm{K} 562$ cells. This indicates that miR-223 may be a negative regulator of AML cell proliferation.

Flow cytometry was performed to evaluate the effect of miR-223 on apoptosis. As presented in Fig. 3, ectopic expression of miR-223 enhanced apoptosis compared with NC in AML cell lines $(\mathrm{P}=0.017$ for HL-60 and $\mathrm{P}=0.010$ for $\mathrm{K} 562)$.

FBXW7 is a direct target gene of $m i R-223$ in AML. To identify the target of miR-223 in AML, a public database (TargetScan; http://www.targetscan.org) was used. FBXW7 was predicted to be a target of miR-223 (Fig. 4A). To verify whether miR-223 directly targeted FBXW7, western blotting was performed to investigate whether FBXW7 was downregulated following transfection of miR-223 into AML HL-60 and K562 cells. As shown in Fig. 4B, FBXW7 was significantly downregulated in AML HL-60 $(\mathrm{P}=0.024)$ and $\mathrm{K} 562(\mathrm{P}=0.032)$ cells following transfection of miR-223.

Furthermore, luciferase reporter assays were conducted. Luciferase reporter assays revealed that miR-223 significantly inhibited the WT ( $\mathrm{P}=0.019$ for HL-60 and $\mathrm{P}=0.270$ for $\mathrm{K} 562)$, 


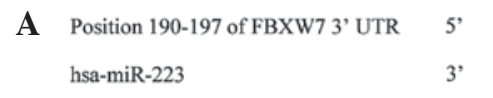

B
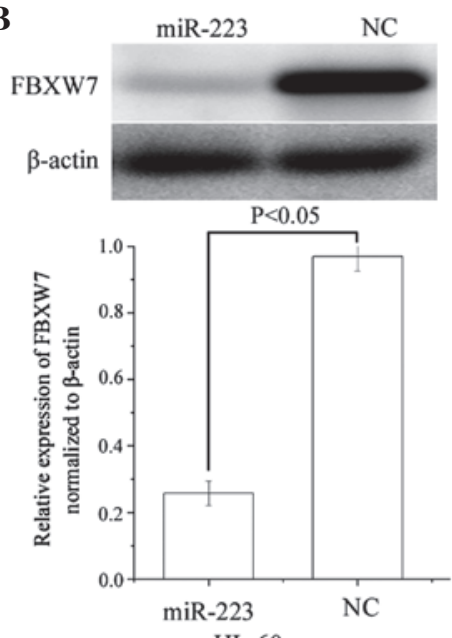

HL-60

C
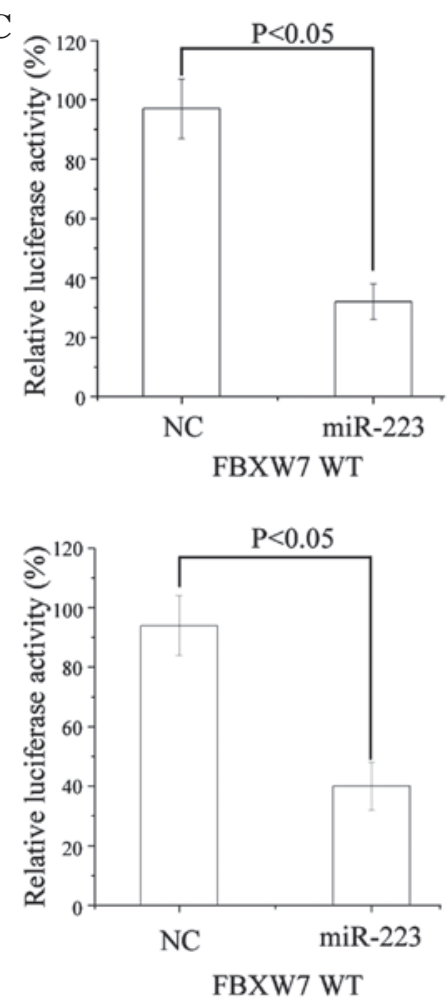
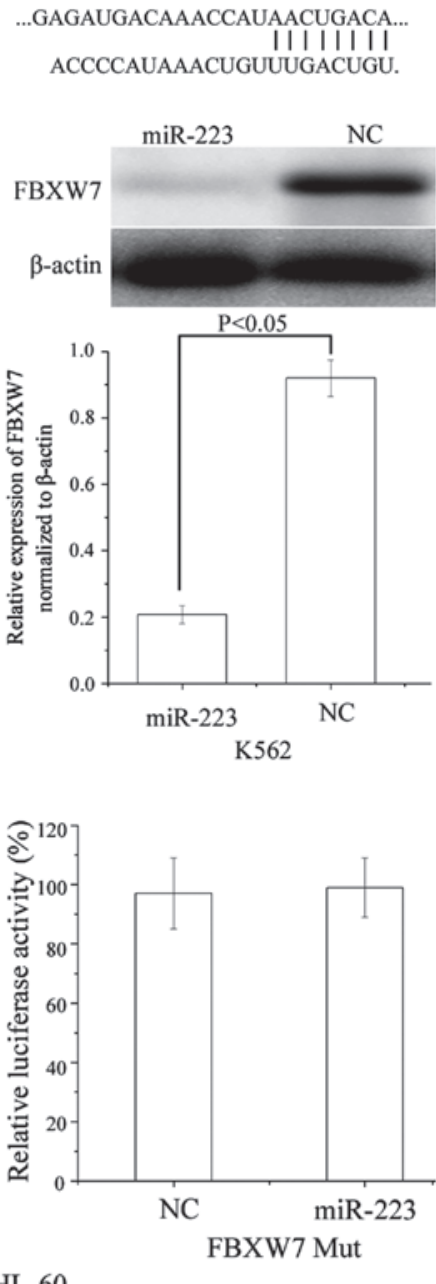

HL-60

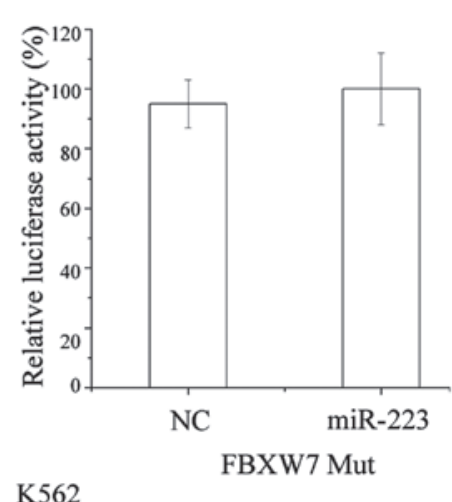

Figure 4. (A) Target Scan assessment that FBXW7 mRNA contained a miR-223 eight-nucleotide seed match at position 190-197 of the FBXW7 3'-UTR. (B) Western blot analysis revealed that FBXW7 was significantly downregulated in AML HL-60 and K562 cells following transfection with miR-223. (C) FBXW7 may be a direct target of miR-223 in vitro. Overexpression of miR-223 significantly inhibited the WT but not the Mut luciferase activity of FBXW7 in AML HL-60 and K562 cells. FBXW7, F-box and WD repeat domain containing 7; miR, microRNA; UTR, untranslated region; AML, acute myeloid leukemia; WT, wild-type; Mut, mutant; NC, negative control.

but not the Mut luciferase activity of FBXW7 in AML HL-60 and K562 cells (Fig. 4C). Taken together, these results appear to indicate that FBXW7 is a direct target gene of miR-223 in AML.

\section{Discussion}

miRNA-223 has a significant role in a number of types of human cancer. It has been observed to be upregulated in a number of types of human cancer, including gastric cancer (26), glioblastoma (27), colorectal cancer (28) and lung cancer (29). Furthermore, Li et al found that gastric cancer patients with lymph node metastasis or organ metastasis demonstrated significantly increased expression of miR-223 (30). The expression of miR-223 was observed to be upregulated in recurrent ovarian cancer (31). Specifically, patients with lymph node metastasis or metastatic disease at an advanced pathological stage exhibited significantly higher expression of miR-223 compared with patients without lymph node metastasis or 
metastatic disease (31). However, downregulation of miR-223 has been observed in various types of cancer, including osteosarcoma (32), hepatocellular carcinoma (33) and esophageal carcinoma (34). These previous findings demonstrate that miR-223 may have a vital role as either a tumor suppressor, or as an oncogenic regulator during tumor progression. It may also be useful as a potential biomarker for cancer.

The results of the present study provide evidence that miR-223 is downregulated in AML, which may indicate that miR-223 has a suppressive role in AML. By inducing overexpression of miR-223 in AML cell lines, the present study demonstrated that miR-223 is able to reduce cell proliferation and promote cell apoptosis, additionally suggesting a suppressive role for miR-223. This suggests that miR-223 may be useful in the development of novel therapies for the treatment of AML.

Identification of miR-223 target genes is critical for understanding its role in tumorigenesis. Previous studies have revealed that miR-223 may regulate transcripts in human cells, including erythrocyte membrane protein band 4.1 like 3 (35), septin 6 (36), FBXW7 (37), ataxia telangiectasia mutated (38), insulin-like growth factor 1 (29), paired box 6 (27) and caprin-1 (27). In the present study, it was demonstrated that miR-223 may function as a tumor suppressor through downregulation of FBXW7 in AML. miR-223 transfection resulted in decreased cell viability and an increase in apoptosis in human AML cell lines. Therefore, these results may have certain clinical implications in the future.

In addition, a significant molecular link between miR-223 and FBXW7 was observed in the present study. Initially, TargetScan predicted that FBXW7 was a direct target gene of miR-223. It was demonstrated that FBXW7 mRNA contained a miR-223 eight-nucleotide seed match at position 190-197 of the FBXW7 3'-UTR. Subsequently, in the luciferase dual-activity assay, miR-223 directly targeted FBXW7 3'-UTR as predicted by bioinformatics. Finally, it was demonstrated that rescue of miR-223 expression led to downregulation of FBXW7 protein in AML cell lines. Taken together, the results of the present study revealed that miR-223 regulated FBXW7 expression in vitro and may act as a suppressive molecule during $\mathrm{AML}$ development and progression.

FBXW7, a well-known F-box protein in the SCF E3 ligase complex, determines target specificity by recognizing and binding proteins, leading to their ubiquitination and proteasomal degradation (39). FBXW7 has been verified to regulate various cellular processes, including cell proliferation, differentiation, cell cycle, migration and invasion, by targeting numerous substrates for degradation (40-42). For example, downregulation of FBXW7 inhibits cell proliferation by controlling cell cycle transition via the degradation of crucial cell-cycle regulators, including c-myc (43), Jun (44), cyclin-E (45) and Notch (46). Consistent with these reports, the present study demonstrated that overexpression of miR-223 had a negative effect on FBXW7 and inhibited cell proliferation, as well as enhancing cell apoptosis. Therefore, the results of the present study establish a functional link between miR-223 and FBXW7, and confirm that miR-223 inhibits AML cell proliferation and that enhanced AML apoptosis is mediated, at least partly, by suppression of FBXW7.

In conclusion, the present study is the first, to the best of our knowledge, to demonstrate that miR-223 is downregulated in
AML. It was additionally demonstrated that miR-223 inhibits cell proliferation and enhances cell apoptosis in AML cells. The identification of candidate target genes of miR-223 may provide an understanding of potential mechanisms underlying the development and progression of AML. The results of the present study have therapeutic implications and may be exploited for the development of novel treatments for AML. Future work is required to address the potential of miR-223 as a target for the treatment of AML.

\section{Acknowledgements}

This present study was supported by the Natural Science Foundation of Hubei Province (grant no. 2012FFB02435) and the Central University Special Funding (grant no. 2013QN191).

\section{References}

1. Estey E and Döhner H: Acute myeloid leukaemia. Lancet 368: 1894-1907, 2006.

2. Smith A, Howell D, Patmore R, Jack A and Roman E: Incidence of haematological malignancy by sub-type: A report from the Haematological Malignancy Research Network. Br J Cancer 105: 1684-1692, 2011

3. Sun Z, Zhang A, Jiang T, Du Z, Che C and Wang F: MiR-145 suppressed human retinoblastoma cell proliferation and invasion by targeting ADAM19. Int J Clin Exp Pathol 8: 14521-14527, 2015.

4. Zhou XU, Qi L, Tong S, Cui YU, Chen J, Huang T, Chen Z and $\mathrm{Zu} \mathrm{XB:}$ miR-128 downregulation promotes growth and metastasis of bladder cancer cells and involves VEGF-C upregulation. Oncol Lett 10: 3183-3190, 2015.

5. Tan G, Wu L, Tan J, Zhang B, Tai WC, Xiong S, Chen W, Yang J and $\mathrm{Li} \mathrm{H}$ : MiR-1180 promotes apoptotic resistance to human hepatocellular carcinoma via activation of NF- $\kappa \mathrm{B}$ signaling pathway. Sci Rep 6: 22328, 2016.

6. Shih AH, Abdel-Wahab O, Patel JP and Levine RL: The role of mutations in epigenetic regulators in myeloid malignancies. Nat Rev Cancer 12: 599-612, 2012.

7. White BS and DiPersio JF: Genomic tools in acute myeloid leukemia: From the bench to the bedside. Cancer 120: 1134-1144, 2014.

8. Rommer A, Steinleitner K, Hackl H, Schneckenleithner C, Engelmann M, Scheideler M, Vlatkovic I, Kralovics R, Cerny-Reiterer S, Valent $\mathrm{P}$, et al: Overexpression of primary microRNA 221/222 in acute myeloid leukemia. BMC Cancer 13: 364, 2013.

9. DiNardo CD and Cortes JE: New treatment for acute myelogenous leukemia. Expert Opin Pharmacother 16: 95-106, 2015.

10. Copsel S, Bruzzone A, May M, Beyrath J, Wargon V, Cany J, Russel FG, Shayo C and Davio C: Multidrug resistance protein 4/ ATP binding cassette transporter 4: A new potential therapeutic target for acute myeloid leukemia. Oncotarget 5: 9308-9321, 2014.

11. Croce CM: MicroRNA dysregulation in acute myeloid leukemia. J Clin Oncol 31: 2065-2066, 2013.

12. Erdogan B, Bosompem A, Peng D, Han L, Smith E, Kennedy ME, Alford $\mathrm{CE}, \mathrm{Wu} \mathrm{H}$, Zhao Z, Mosse CA, et al: Methylation of promoters of microRNAs and their host genes in myelodysplastic syndromes. Leuk Lymphoma 54: 2720-2727, 2013.

13. Alemdehy MF and Erkeland SJ: MicroRNAs: Key players of normal and malignant myelopoiesis. Curr Opin Hematol 19: 261-267, 2012.

14. Vasilatou D, Papageorgiou S, Pappa V, Papageorgiou E and Dervenoulas J: The role of microRNAs in normal and malignant hematopoiesis. Eur J Haematol 84: 1-16, 2010.

15. Shibayama Y, Kondo T, Ohya H, Fujisawa S, Teshima T and Iseki K: Upregulation of microRNA-126-5p is associated with drug resistance to cytarabine and poor prognosis in AML patients. Oncol Rep 33: 2176-2182, 2015.

16. Jansson MD and Lund AH: MicroRNA and cancer. Mol Oncol 6: 590-610, 2012.

17. Nana-Sinkam SP and Croce CM: Clinical applications for microRNAs in cancer. Clin Pharmacol Ther 93: 98-104, 2013. 
18. Chen Y, Jacamo R, Konopleva M, Garzon R, Croce C and Andreeff M: CXCR4 downregulation of let-7a drives chemoresistance in acute myeloid leukemia. J Clin Invest 123: 2395-2407, 2013.

19. Li $\mathrm{X}$ and Zhong H: The diagnosis, prognosis, and therapeutic application of MicroRNAs in haematological malignancies. Hematology 21: 263-271, 2016.

20. Wang XX, Wang Y, Wang PP and Li Y: Expression of microRNA-148/152 family in the mematological malignancies. Zhongguo Shi Yan Xue Ye Xue Za Zhi 23: 1173-1178, 2015 (In Chinese).

21. Amodio N, Rossi M, Raimondi L, Pitari MR, Botta C, Tagliaferri P and Tassone P: miR-29s: A family of epi-miRNAs with therapeutic implications in hematologic malignancies. Oncotarget 6: 12837-12861, 2015.

22. Sabattini E, Bacci F, Sagramoso C and Pileri SA: WHO classification of tumours of haematopoietic and lymphoid tissues in 2008: An overview. Pathologica 102: 83-87, 2010.

23. Lo Coco F and Foa R: Diagnostic and prognostic advances in the immunophenotypic and genetic characterization of acute leukaemia. Eur J Haematol 55: 1-9, 1995

24. Bennett JM, Catovsky D, Daniel MT, Flandrin G, Galton DA, Gralnick HR and Sultan C: Proposed revised criteria for the classification of acute myeloid leukemia. A report of the French-American-British cooperative group. Ann Intern Med 103: 620-625, 1985.

25. Livak and Schmittgen: Analysis of relative gene expression data using real-time quantitative PCR and the $2-\Delta \Delta \mathrm{Ct}$ method. Methods 25: 402-408, 2001

26. Li BS, Zhao YL, Guo G, Li W, Zhu ED, Luo X, Mao XH, Zou QM, Yu PW, Zuo QF, et al: Plasma microRNAs, miR-223, miR-21 and miR-218, as novel potential biomarkers for gastric cancer detection. PLoS One 7: e41629, 2012.

27. Huang BS, Luo QZ, Han Y, Li XB, Cao LJ and Wu LX microRNA-223 promotes the growth and invasion of glioblastoma cells by targeting tumor suppressor PAX6. Oncol Rep 30: 2263-2269, 2013.

28. Wu L, Li H, Jia CY, Cheng W, Yu M, Peng M, Zhu Y, Zhao Q, Dong YW, Shao K, et al: MicroRNA-223 regulates FOXO1 expression and cell proliferation. FEBS Lett 586: 1038-1043, 2012.

29. Nian W, Ao X, Wu Y, Huang Y, Shao J, Wang Y, Chen Z, Chen F and Wang D: miR-223 functions as a potent tumor suppressor of the Lewis lung carcinoma cell line by targeting insulin-like growth factor-1 receptor and cyclin-dependent kinase 2. Oncol Lett 6: 359-366, 2013.

30. Li J, Guo Y, Liang X, Sun M, Wang G, De W and Wu W: MicroRNA-223 functions as an oncogene in human gastric cancer by targeting FBXW7/hCdc4. J Cancer Res Clin Oncol 138: 763-774, 2012

31. Laios A, O'Toole S, Flavin R, Martin C, Kelly L, Ring M, Finn SP, Barrett C, Loda M, Gleeson N, et al: Potential role of miR-9 and miR-223 in recurrent ovarian cancer. Mol Cancer 7: 35, 2008
32. Namløs HM, Meza-Zepeda LA, Barøy T, Østensen IH, Kresse SH, Kuijjer ML, Serra M, Bürger H, Cleton-Jansen AM and Myklebost O: Modulation of the osteosarcoma expression phenotype by microRNAs. PLoS One 7: e48086, 2012.

33. Karakatsanis A, Papaconstantinou I, Gazouli M, Lyberopoulou A, Polymeneas G and Voros D: Expression of microRNAs, miR-21, miR-31, miR-122, miR-145, miR-146a, miR-200c, miR-221, miR-222, and miR-223 in patients with hepatocellular carcinoma or intrahepatic cholangiocarcinoma and its prognostic significance. Mol Carcinog 52: 297-303, 2013.

34. Li S, Li Z, Guo F, Qin X, Liu B, Lei Z, Song Z, Sun L, Zhang HT, You J and Zhou Q: miR-223 regulates migration and invasion by targeting Artemin in human esophageal carcinoma. J Biomed Sci 18: 24, 2011

35. Liang H, Yan X, Pan Y, Wang Y, Wang N, Li L, Liu Y, Chen X, Zhang $\mathrm{CY}, \mathrm{Gu} \mathrm{H}$ and Zen K: MicroRNA-223 delivered by platelet-derived microvesicles promotes lung cancer cell invasion via targeting tumor suppressor EPB41L3. Mol Cancer 14: 58, 2015.

36. Wei Y, Yang J, Yi L, Wang Y, Dong Z, Liu Z, Ou-yang S, Wu H, Zhong Z, Yin Z, et al: MiR-223-3p targeting SEPT6 promotes the biological behavior of prostate cancer. Sci Rep 4: 7546, 2014.

37. Zhou X, Jin W, Jia H, Yan J and Zhang G: MiR-223 promotes the cisplatin resistance of human gastric cancer cells via regulating cell cycle by targeting FBXW7. J Exp Clin Cancer Res 34: 28, 2015.

38. Liang L, Zhu J, Zaorsky NG, Deng Y, Wu X, Liu Y, Liu F, Cai G, $\mathrm{Gu} \mathrm{W}$, Shen L and Zhang Z: MicroRNA-223 enhances radiation sensitivity of U87MG cells in vitro and in vivo by targeting ataxia telangiectasia mutated. Int J Radiat Oncol Biol Phys 88: 955-960, 2014.

39. Wang Z, Inuzuka H, Zhong J, Wan L, Fukushima H, Sarkar FH and Wei W: Tumor suppressor functions of FBW7 in cancer development and progression. FEBS Lett 586: 1409-1418, 2012.

40. Lau AW, Fukushima $\mathrm{H}$ and Wei W: The Fbw7 and betaTRCP E3 ubiquitin ligases and their roles in tumorigenesis. Front Biosci (Landmark Ed) 17: 2197-2212, 2012

41. Welcker M and Clurman BE: FBW7 ubiquitin ligase: A tumour suppressor at the crossroads of cell division, growth and differentiation. Nat Rev Cancer 8: 83-93, 2008.

42. Minella AC and Clurman BE: Mechanisms of tumor suppression by the SCF(Fbw7). Cell Cycle 4: 1356-1359, 2005.

43. Yada M, Hatakeyama S, Kamura T, Nishiyama M, Tsunematsu R, Imaki H, Ishida N, Okumura F, Nakayama K and Nakayama KI: Phosphorylation-dependent degradation of c-Myc is mediated by the F-box protein Fbw7. EMBO J 23: 2116-2125, 2004.

44. Nateri AS, Riera-Sans L, Da Costa C and Behrens A: The ubiquitin ligase SCFFbw7 antagonizes apoptotic JNK signaling. Science 303: 1374-1378, 2004.

45. Koepp DM, Schaefer LK, Ye X, Keyomarsi K, Chu C, Harper JW and Elledge SJ: Phosphorylation-dependent ubiquitination of cyclin E by the SCFFbw7 ubiquitin ligase. Science 294: 173-177, 2001.

46. Fryer CJ, White JB and Jones KA: Mastermind recruits CycC:CDK8 to phosphorylate the Notch ICD and coordinate activation with turnover. Mol Cell 16: 509-520, 2004. 